\title{
Predicting intention to receive COVID-19 vaccine among the general population using the health belief model and the theory of planned behavior model
}

\author{
Liora Shmueli
}

\begin{abstract}
Background: This study aim to explore the intentions, motivators and barriers of the general public to vaccinate against COVID-19, using both the Health Belief Model (HBM) and the Theory of Planned Behavior (TPB) model.

Methods: An online survey was conducted among Israeli adults aged 18 years and older from May 24 to June 24, 2020. The survey included socio-demographic and health-related questions, questions related to HBM and TPB dimensions, and intention to receive a COVID-19 vaccine. Associations between questionnaire variables and COVID19 vaccination intention were assessed by univariate and multivariate analyses.

Results: Eighty percent of 398 eligible respondents stated their willingness to receive COVID-19 vaccine. A unified model including HBM and TPB predictor variables as well as demographic and health-related factors, proved to be a powerful predictor of intention to receive COVID-19 vaccine, explaining $78 \%$ of the variance (adjusted $\mathrm{R}$ squared $=0.78)$. Men $(\mathrm{OR}=4.35,95 \% \mathrm{Cl} 1.58-11.93)$, educated respondents $(\mathrm{OR}=3.54,95 \% \mathrm{Cl} 1.44-8.67)$ and respondents who had received the seasonal influenza vaccine in the previous year $(\mathrm{OR}=3.31,95 \% \mathrm{Cl} 1.22-9.00)$ stated higher intention to receive COVID-19 vaccine. Participants were more likely to be willing to get vaccinated if they reported higher levels of perceived benefits of COVID-19 vaccine (OR $=4.49,95 \% \mathrm{Cl}$ 2.79-7.22), of perceived severity of COVID-19 infection ( $\mathrm{OR}=2.36,95 \% \mathrm{Cl} 1.58-3.51)$ and of cues to action ( $\mathrm{OR}=1.99,95 \% \mathrm{Cl} 1.38-2.87)$, according to $\mathrm{HBM}$, and if they reported higher levels of subjective norms $(\mathrm{OR}=3.04,95 \% \mathrm{Cl} 2.15-4.30)$ and selfefficacy (OR $=2.05,95 \% \mathrm{Cl} 1.54-2.72)$ according to TPB. Although half of the respondents reported they had not received influenza vaccine last year, $40 \%$ of them intended to receive influenza vaccine in the coming winter and $66 \%$ of them intended to receive COVID-19 vaccine.

Conclusions: Providing data on the public perspective and predicting intention for COVID-19 vaccination using HBM and TPB is important for health policy makers and healthcare providers and can help better guide compliance as the COVID-19 vaccine becomes available to the public.
\end{abstract}

Keywords: Vaccine acceptance, SARS-CoV-2, Theoretical behavior models, Hierarchical logistic regression 


\section{Background}

On March 11, 2020, the World Health Organization (WHO) declared a novel strain of coronavirus (COVID19) as a global pandemic [1]. At the time of conducting this study (June 2020), no vaccine to COVID-19 has become available yet, and such vaccines were estimated to become available only at the end of 2021 [2]. However, sooner than expected, in December 2020, the U.S. Food and Drug Administration (FDA) authorized a vaccine to COVID-19 by Pfizer-BioNTech [3]. This authorization was quickly followed by authorizations to other vaccines by Moderna, AstraZeneca/Oxford and Jansen. Immediately after the first vaccine became available, mass vaccination campaigns against COVID-19 were initiated around the world. Particularly, in Israel, which was among the first countries to initiate such a campaign, more than $49 \%$ of people have received at least the first dose by the end of February 2021 [4].

Nevertheless, even with the availability of COVID-19 vaccines, some part of the public is not expected to get vaccinated, mainly due to a phenomenon known as vaccine hesitancy [5], therefore it is of utmost priority to understand the intentions, motivators and barriers that influence the general public to vaccinate against COVID-19. Such understanding would help prepare intervention plans based on accessibility to the general public while targeting populations that show a tendency not to get vaccinated.

Several studies have examined the intention of the public to get vaccinated with COVID-19 vaccine. A study conducted in Europe, involving participants from Denmark, France, Germany, Italy, Portugal, the Netherlands, and the UK, demonstrated a high response rate of $74 \%$ [6]. A higher response rate of $86 \%$ was found in Australia [7], while a lower rate of $69 \%$ was found among adults in the United States [8]. In considering the factors associated with willingness to be vaccinated against COVID-19, one can divide them into demographic and health-related predictors and predictors based on theoretical behavior models.

\section{Demographic and health-related predictors}

Recent studies addressing predictors of intention to receive COVID-19 vaccine have shown that significantly higher proportion of men were willing to get vaccinated (77.9\%) than women (70.1\%), especially among men above the age of 55 [6]. Likewise, individuals considering themselves at risk for the disease [9] and those who reported their healthcare provider would recommend they get vaccinated against COVID-19 [8] were more likely to self-report acceptability to receive COVID-19 vaccination. While a relatively small number of studies have investigated the willingness to receive a vaccine against COVID-19, many studies have investigated acceptance of influenza vaccine. In the present study, aimed at determining the willingness to receive a COVID-19 vaccine, I adopted some of the factors studied in the case of influenza vaccine.

The literature reports several dominant characteristics that describe patients who intended to get an influenza vaccine. Males are apparently more willing to get vaccinated than are woman $[10,11]$ and older patients above the age of 65 are more willing to get vaccinated than are younger patients [12]. At the same time, more educated patients and those having high income levels are willing to get vaccinated [13, $14]$, as are those having chronic health conditions and who perceived their health to be less good [15]. Other characteristics, such as living alone with no partner or children and being unmarried, were negatively associated with the desire to get vaccinated [11].

Nevertheless, it is interesting to explore the impact of theoretical behavior models beyond demographic and health related predictors.

\section{Predictors based on theoretical behavior models}

Theoretical models of health beliefs and risk perception are essential tools for understanding the factors behind decision-making by assessing what motivates and inhibits people to adopt health-related behavior. HBM is one of the most widely used models for examining the relationship between health behavior and the use of health services. It was developed in the 1950 s by social psychologists at the U.S. Public Health Service [16]. This strategy seeks to explain and predict preventive health behavior in terms of certain belief patterns. Specifically, HBM suggests that an individuals' engagement (or lack of engagement) in health-promoting behavior can be explained by their beliefs about health problems, perceived benefits of action and barriers to action, and selfefficacy. A cue to action, must also be present in order to trigger the health-promoting behavior. HBM has been widely used in the context of vaccination, and particularly in the context of influenza vaccination. A systematic review conducted by Bish et al., 2011 examined the psychological and demographic factors associated with uptake of influenza vaccination, demonstrated the extensive use of the HBM $[10,17,18]$. In the same context of the intention to vaccinate against influenza, perceived susceptibility refers to the individual's perception regarding the chance of being infected by influenza. At one end of the scale one finds individuals who deny the possibility of infection, while at the other end one finds people who feel the danger of infection. In previous studies, this predictor was found to be a significant predictor for refusing a vaccine (43.2\%), of patient perception of not being at risk for influenza, bias with a sense of disease resistance, and a low chance of the individual 
getting sick. Perceived severity refers to the individual's belief as to difficulties that the disease may create medically and socially, for example, pain, missing workdays, etc. Perceived barriers refer to the individual's perceived negative aspects related to the action of getting vaccinated, such as expenses, physical pain, psychological considerations or a logistic lack of access [11, 19]. Cues to action is the last predictor that completes the behavioral change proposed in the original HBM, and include the presence of internal or external incentives that serve to motivate vaccination, such as information from the mass media or a doctor who recommends taking the vaccine [20].

TPB is another theoretical model used to predict an individual's behavior in terms of intention to get vaccinated. The model was proposed by Icek Ajzen as a successor of the Theory of Reasoned Action [21]. According to the TPB model, the intention to get an influenza vaccination depends on a number of predictors, including the attitude towards the vaccine, subjective norms for carrying out vaccination, and perception of behavioral control (PBC) of vaccination. Self-efficacy for vaccination is another predictor that was added to the original model, as it has been proven that a distinction must be made between perception of control of behavior and self-efficacy. Self-efficacy was found to be the most important predictor for health behavioral intention [22, 23]. A few recent studies have combined the TPB and HBM approaches to identify health-related behaviors and intention to receive influenza vaccine among the general public [19, 24, 25].

In the context of COVID-19, several health beliefs have also been correlated with vaccine acceptability. For example, study participants who reported higher levels of perceived likelihood of getting a COVID-19 infection in the future and who perceived the severity of COVID19 infection were more likely to be willing to get vaccinated [8]. The perceived benefit construct in the HBM was also found to be significant in predicting acceptance of the vaccine [26]. However, although several studies have used the TPB model in the context of linking COVID-19 with preventive behaviors (e.g. social distancing, washing hands, etc.) $[27,28]$, I'm not aware of any study using this model to predict COVID-19 vaccine acceptability. I'm also not aware of any study in which both models were used to identify the factors of the general public's willingness to receive a COVID-19 vaccine.

\section{Aims and scope}

The aims of the present study were to investigate attitudes and beliefs of the general public regarding a future COVID-19 vaccination, and to identify the determining factors, motivators and barriers leading to the decision to receive vaccination or not, by including factors adopted from the case of influenza, together with the combined use of the HBM and TPB models.

\section{Methods \\ Study participants and survey design}

I conducted a cross-sectional national anonymous web-based survey using an electronic questionnaire, distributed via online social platforms (Google, Facebook and WhatsApp) among the general Israeli adult population (i.e., 18 years old or older). The survey was conducted between May 24 and June 26, after the Israeli government announced a variety of restrictions in May 2020. These strict restrictions, including lockdown, obligation to wear a mask, etc., were decreed during March-April, following the proclamation of COVID-19 as a global pandemic. At that time, COVID-19 vaccines were still under development, with 26 different vaccines in the human trial phase, according to the WHO [2].

Before distributing the questionnaire to the general public, the questionnaire was pilot-tested by a panel of experts in the field, including a statistician, a behavioral psychologist and an epidemiologist. Specifically, the experts proofread the questionnaire and ascertained its content validity in terms of the fit between each statement in the questionnaire and the corresponding theoretical variable. The questionnaire was then amended according to the comments raised by the experts.

\section{Questionnaire}

The following sections describe the dependent and independent variables and their operationalization in this study. Health belief measures were adopted from another study based on the HBM and TPB models [16, 21].

The parameters comprising the study measurements were used to build the conceptual model (see Fig. 1) and are described below.

The questionnaire consisted of the following sections: (1) socio-demographic predictor variables; (2) health-related predictor variables (3); HBM predictor variables (4) TPB predictor variables; (5) intention to receive a future COVID-19 vaccine; and (6) intention to receive an influenza vaccine. Overall, the questionnaire consisted of 45 questions and took less than 10 min to complete.

\section{Variables and measurements}

The dependent variable was the intention to receive a future COVID-19 vaccine, originally measured by a one-item question on a 1-6 scale (1 - not appropriate at all, 6 - very appropriate). This variable was transformed to a binary variable ( 1 - intends to get vaccinated, 0 - does not intend to get vaccinated) in order 
Sociodemographic variables

(1) Age
(2) Gender
(3) Education
(4) Personal status
(5) Socioeconomic level
(6) Periphery level
(7) Being an immigrant
(8) Country of birth
(9) Number of children
(10) Medical staff

(10) Medical staff

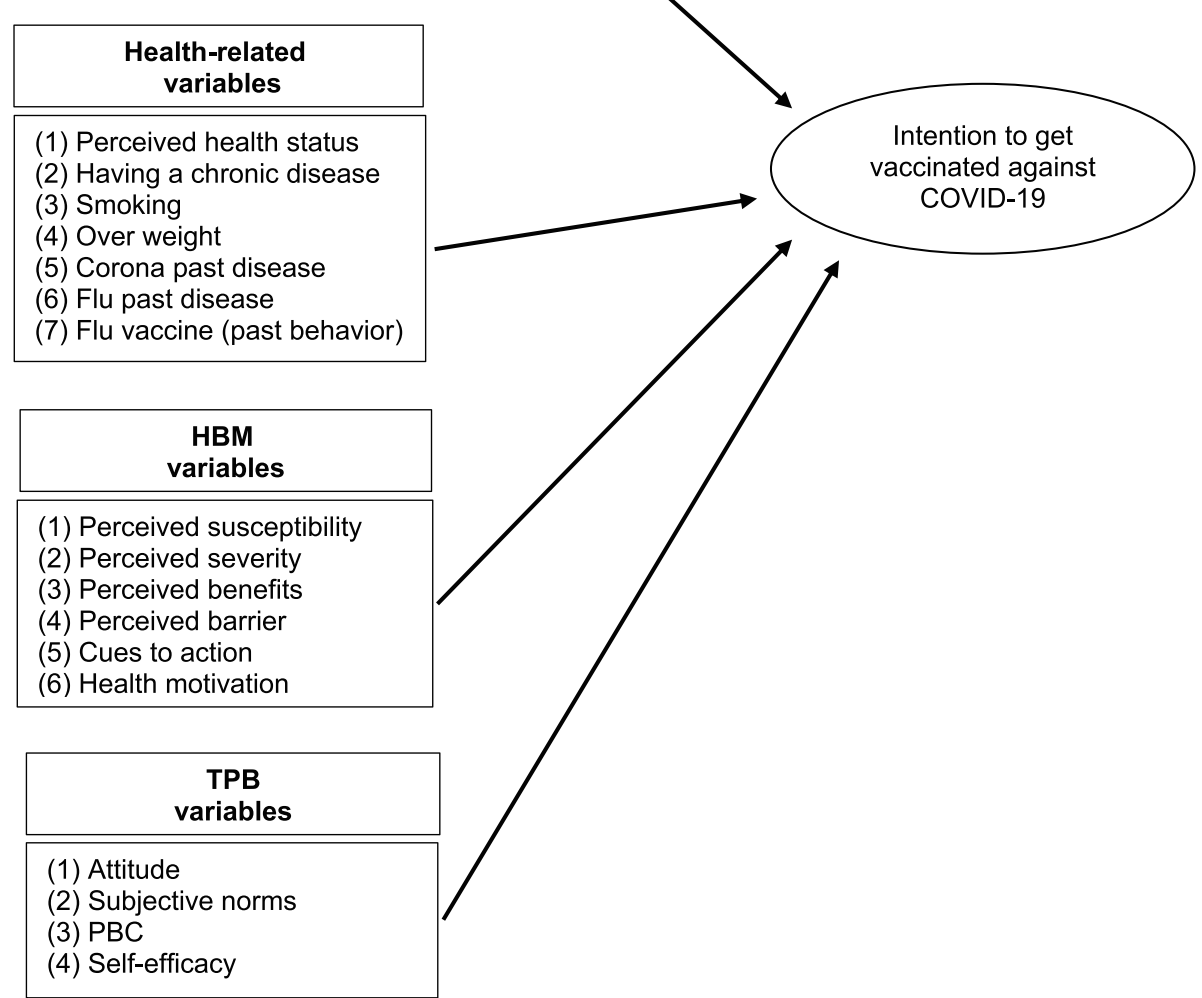

Fig. 1 Conceptual framework for the hypothesized predictors of the intention to receive a COVID-19 vaccine

to simplify our analyses, in terms of being able to compare individuals that intended to get vaccinated with those who did not.

The independent variables were grouped into four blocks:

(1) The socio demographic predictor variables were: (1) age; (2) gender; (3) education level; (4) personal status (in partnership or not; with or without children); (5) socio-economic level, based on the Israeli Central Bureau of Statistics scale; (6) periphery level, defined by residential area; (7) being an immigrant (defined as immigration to Israel after 1989);

(8) number of children; and (9) being medical staff or not. The age variable was transformed from numeric to categorical $(18-39 ; 40-64,65+)$ in order to examine differences between specific age groups. ${ }^{1}$

(2) The health-related predictor variables were: (1) perceived health status; (2) having a chronic disease (one or more of the following: heart disease, vascular disease and / or stroke, diabetes mellitus, hypertension, chronic lung disease including asthma or immune suppression); (3) smoking; (4) being over-weight; (5) past episodes of COVID19; (6) past episodes of influenza; and (7) having

\footnotetext{
${ }^{1}$ According to the CDC older adults (people aged 65 years and older) are at higher risk for severe illness from COVID-19, while young adults, ages 18-39 have a considerably lower risk for covid-19 severe morbidity [29].
} 
Table 1 Items, response scales and internal consistency for assessing measures of the two theoretical behavior models: HBM and TPB

\begin{tabular}{|c|c|c|c|c|c|}
\hline Model & Measures & Items & Mean & Std & a \\
\hline \multirow[t]{14}{*}{ HBM } & \multirow{2}{*}{$\begin{array}{l}\text { Perceived } \\
\text { susceptibility }\end{array}$} & I believe that if I do not get vaccinated, the likelihood of me getting infected with corona will increase & 4.58 & 1.59 & \multirow[t]{2}{*}{0.83} \\
\hline & & $\begin{array}{l}\text { I believe that if I do not get vaccinated, the likelihood of my family and relatives getting infected in } \\
\text { Corona will increase }\end{array}$ & 4.50 & 1.55 & \\
\hline & \multirow[t]{2}{*}{$\begin{array}{l}{ }^{\text {a }} \text { Perceived } \\
\text { severity }\end{array}$} & $\begin{array}{l}\text { Even if I will get infected with COVID-19 I do not think it will cause me significant suffering or } \\
\text { complications }\end{array}$ & 3.74 & 1.66 & \multirow[t]{2}{*}{0.73} \\
\hline & & Even if I get infected with COVID-19, the likelihood of recovering from the disease is very high & 2.63 & 1.38 & \\
\hline & \multirow[t]{2}{*}{$\begin{array}{l}\text { Perceived } \\
\text { benefits }\end{array}$} & $\begin{array}{l}\text { I believe that COVID-19 vaccine will have high efficacy in preventing significant suffering and complica- } \\
\text { tions of the disease }\end{array}$ & 4.87 & 1.40 & \multirow[t]{2}{*}{0.87} \\
\hline & & $\begin{array}{l}\text { I believe that if I get vaccinated against COVID-19 the risk of getting infected with the disease or in- } \\
\text { fecting others will decrease }\end{array}$ & 4.97 & 1.39 & \\
\hline & $\begin{array}{l}\text { Perceived } \\
\text { barriers }\end{array}$ & Getting vaccinated is expensive, requires time and effort & 2.44 & 1.53 & - \\
\hline & \multirow[t]{5}{*}{ Cues to action } & $\begin{array}{l}\text { The chances of me getting vaccinated against COVID-19 will increase if opinion leaders on social } \\
\text { media express support for the benefit of the vaccine }\end{array}$ & 2.98 & 1.94 & \multirow[t]{5}{*}{0.79} \\
\hline & & $\begin{array}{l}\text { The chances of me getting vaccinated against COVID-19 will increase if friends and family express sup- } \\
\text { port for the benefit of the vaccine }\end{array}$ & 3.63 & 1.83 & \\
\hline & & $\begin{array}{l}\text { The chances of me getting vaccinated against COVID-19 will increase if official guidelines from the } \\
\text { Ministry of Health are published }\end{array}$ & 4.44 & 1.72 & \\
\hline & & The chances of me getting vaccinated against COVID-19 will increase if my GP recommends me & 4.29 & 1.77 & \\
\hline & & If my workplace takes care of vaccinating the workers against COVID-19, I will vaccinate & 4.48 & 1.90 & \\
\hline & \multirow{2}{*}{$\begin{array}{l}\text { Health } \\
\text { motivation }\end{array}$} & I exercise as recommended for my age & 3.90 & 1.70 & \multirow[t]{2}{*}{0.75} \\
\hline & & I make sure to eat a healthy and varied diet & 4.24 & 1.39 & \\
\hline \multirow[t]{5}{*}{ TPB } & Attitude & Getting vaccinated is a tedious process that requires time and effort & 2.44 & 1.53 & - \\
\hline & \multirow{2}{*}{$\begin{array}{l}\text { Subjective } \\
\text { norms }\end{array}$} & Most of my friends will support the COVID-19 vaccine & 4.68 & 1.28 & \multirow[t]{2}{*}{0.86} \\
\hline & & $\begin{array}{l}\text { If I tell my friends and relatives that I intend to get vaccinated against COVID-19 when a vaccine is } \\
\text { available, they will respond positively }\end{array}$ & 4.99 & 1.23 & \\
\hline & PBC & $\begin{array}{l}\text { If I am offered a vaccine against COVID-19 for the coming winter, I'm sure I'll be vaccinated, and this } \\
\text { decision is entirely up to me. }\end{array}$ & 5.05 & 1.29 & - \\
\hline & Self-efficacy ${ }^{a}$ & $\begin{array}{l}\text { If I take all the necessary precautions (disinfection of hands, etc.) I do not need to be vaccinated } \\
\text { against corona }\end{array}$ & 4.87 & 1.33 & - \\
\hline
\end{tabular}

a Cronbach indicates the internal consistency: HBM $a=0.77$, TPB $a=0.60$

Items Response scale: 1-6 agreement

${ }^{a}$ Negative items were reverse scored

received influenza vaccine last year (i.e., past behavior).

(3) The HBM predictor variables were (Table 1): (1) perceived susceptibility (included two items, Cronbach $\alpha=0.83$ ); (2) perceived severity (included two items, Cronbach $\alpha=0.73$ ); (3) perceived benefits (included two items, Cronbach $\alpha=0.87$ ); (4) perceived barriers (included one item); (5) cues to action (included five items, Cronbach $\alpha=0.79$ ); (6) health motivation (included two items, Cronbach $\alpha=0.75$ ), a dimension added to the original model. Not many studies include this consideration as a model variable [23].

(4) The TPB predictor variables were (Table 1): (1) attitude (included one item); (2) subjective norms (included two items, Cronbach $\alpha=0.86$ ); (3) PBC (Perceived Behavioral Control) and (4) self-efficacy.
The last two predictor variables included one item each, and correspond to dimensions added to the original model [23].

Items in the HBM and TPB models were measured on a 1-6 scale (1- not appropriate at all, 6 very appropriate). ${ }^{2}$ Negative items were reversescored. Scores for each item were averaged to obtain each of the HBM- and TPB-independent categories.

\footnotetext{
${ }^{2}$ Studies in this field typically measure items in the HBM and TPB models using a five-point Likert's scale (from strongly disagree to strongly agree). One weakness of the Likert scale is that participants may avoid extreme response categories, leading to a central tendency bias [30].
} 


\section{Reliability of the questionnaire}

A Cronbach $\alpha$ internal reliability method revealed the internal consistency of HBM to be Cronbach $\alpha=0.77$ and of TPB to be Cronbach $\alpha=0.60$. (Table 1 ).

\section{Statistical analyses}

The data from the electronic questionnaires were imported into the SPSS 26 software and were identified by code alone. Data processing and analysis was done using SPSS 26 software. To test the reliability of HBM and TPB measures, Cronbach's $\alpha$ test was used. To describe the study population characteristics, the following methods of descriptive statistics were used: frequencies, percentages, averages and standard deviations.

Relationships between dependent and independent variables were examined by univariate analyses, using either t-tests on independent samples or Chi squared tests, depending on the characteristics of the examined variable.

To investigate determinants of intention to receive a COVID-19 vaccine, a hierarchical logistic regression was performed. The intention to receive a COVID-19 vaccine was used as the dependent variable. With regard to the independent variables, only variables that were found in the univariate analyses to be significantly correlated $(p<.05)$ with intention to receive the COVID-19 vaccine were included in the regression. These variables were divided into four blocks. Socio-demographic variables were entered into the first block, health-related factors were entered into the second block, followed by key variables from the HBM and the TPB models which entered into the third and fourth blocks, respectively.

\section{Results}

\section{Participants characteristics}

Descriptive characteristics of the respondents are provided in Table 2. Overall, 398 respondents completed the survey, $60 \%$ of whom were female $(n=238)$. The average age of those included in the sample was 42.9 years $(\mathrm{SD}=14.7)$, with half of the participants aged 18 39 years. The majority of those included hold an academic degree $(n=295)$ and most live with a partner (77\%). $16.6 \%$ of respondents $(n=66)$ stated that they suffer from at least one chronic disease, most suffering from hypertension (41.5\%) or Diabetes mellitus (20.7\%). A third of the respondents were overweight $(n=128)$. Only $2 \%$ of participants indicated previous COVID-19 infection.

\section{Willingness to receive COVID-19 and influenza vaccines}

Overall, $80 \%$ of participants were willing to receive COVID-19 vaccine $(n=320) .48 \%$ of participants $(n=$ 193) reported having received influenza vaccine in the previous season. Here, the rates reported for individuals aged 65 and above were significantly higher than for younger respondents aged $18-39$ years $(77 \%$ vs. $43 \%, p<$ $0.05)$. Although $52 \%(n=205)$ reported having decided not to receive influenza vaccine in the previous season, $40 \%$ of them indicated that they would be willing to get influenza vaccine in the coming winter and $66 \%$ of them reported they intended to get COVID-19 vaccine, once available.

\section{Univariate analyses}

Results of the univariate analyses between sociodemographic and health-related variables and willingness to get vaccinated against COVID-19 are reported in Table 2.

The predictor variables that were found to have a statistically significant effect $(p<0.05)$ on intention to receive COVID-19 vaccine were age group, gender, educational level, suffering from a chronic disease, being over-weight and having received influenza vaccine in the previous season. Predictor variables that were not found to be statistically significant include personal status, immigration, periphery level, socio-economic level, number of children, being medical staff, smoking, past episodes of COVID-19 or influenza, or perceived health status.

Results of the univariate analyses between HBM and TPB variables and the intention to get vaccinated against COVID-19 are reported in Table 3. Specifically, Table 3 shows the mean values of HBM and TPB predictor variables, as values on a 1-6 agreement scale, reflecting the intention to receive COVID-19 vaccine. The results in Table 3 indicate that according to HBM, those who intend to get COVID-19 vaccine, on average, perceived COVID-19 to be a more serious illness than those who did not intend to take the vaccine. The former group was more susceptible to illness, perceived a higher risk of infection, perceived more benefits from vaccination, and had higher levels of cues to action. There was no significant difference between the two groups in terms of perceived barriers and health motivation. According to the TPB model, those who intend to get COVID-19 vaccine, on average, reported higher levels of subjective norms than those who did not intend to take the vaccine. The former group also reported higher levels of self-efficacy regarding the vaccine. There was no significant difference between the two groups in terms of attitude and PBC.

\section{Factors associated with intention to receive COVID-19 vaccine}

Our first model, which included HBM variables as well as demographic and health-related factors (Table 4; model 1), explained $74 \%$ of the variance in intention to receive COVID-19 vaccine (adjusted $\mathrm{R}$ squared $=0.74$ ). The most important components of the hierarchical 
Table 2 Characteristics of respondents by intention to get vaccinated against COVID-19 $(n=398)$

\begin{tabular}{|c|c|c|c|c|}
\hline & $\begin{array}{l}\text { All subjects } \\
(n=398)\end{array}$ & $\begin{array}{l}\text { DO not intend to get vaccinated } \\
\text { against COVID-19 } \\
N=78(20 \%)\end{array}$ & $\begin{array}{l}\text { Intend to get vaccinated } \\
\text { against COVID-19 } \\
N=320(80 \%)\end{array}$ & $p$-value \\
\hline & $\mathrm{N}(\%)$ & $\mathrm{N}(\%)$ & $\mathrm{N}(\%)$ & \\
\hline \multicolumn{5}{|l|}{ Sociodemographic } \\
\hline Age group & & & & $0.031^{*}$ \\
\hline 18 thru 39 & $202(50.8 \%)$ & $48(23.8 \%)$ & $154(76.2 \%)$ & \\
\hline 40 thru 64 & $153(38.4 \%)$ & $27(17.6 \%)$ & $126(82.4 \%)$ & \\
\hline $65+$ & $43(10.8 \%)$ & $3(7.0 \%)$ & $40(93.0 \%)$ & \\
\hline Gender & & & & $0.001^{*}$ \\
\hline Male & $160(40.2 \%)$ & $18(11.3 \%)$ & $142(88.8 \%)$ & \\
\hline Female & $238(59.8 \%)$ & $60(25.2 \%)$ & $178(74.8 \%)$ & \\
\hline Educational level & & & & $<0.001^{*}$ \\
\hline Non-academic & $103(25.9 \%)$ & 37 (35.9\%) & $66(64.1 \%)$ & \\
\hline Academic & $295(74.1 \%)$ & $41(13.9 \%)$ & $254(86.1 \%)$ & \\
\hline Personal status-partnership & & & & 0.543 \\
\hline Living with a partner & $306(76.9 \%)$ & $62(20.3 \%)$ & $244(79.7 \%)$ & \\
\hline Not living with a partner & $92(23.1 \%)$ & $16(17.4 \%)$ & $76(82.6 \%)$ & \\
\hline Personal status-living with a child & & & & 0.549 \\
\hline Living with a chilled & $255(64.1 \%)$ & $52(20.40 \%)$ & $203(79.60 \%)$ & \\
\hline Not living with a chilled & $143(35.9 \%)$ & $26(18.20 \%)$ & $117(81.80 \%)$ & \\
\hline Socioeconomic level & & & & 0.482 \\
\hline Low & $31(7.8 \%)$ & $6(19.4 \%)$ & $25(80.6 \%)$ & \\
\hline Medium & $170(42.7 \%)$ & $37(21.8 \%)$ & $133(78.2 \%)$ & \\
\hline High & $191(48.0 \%)$ & $32(16.8 \%)$ & $159(83.2 \%)$ & \\
\hline Peripheral level & & & & 0.779 \\
\hline Periphery & $33(8.3 \%)$ & $7(21.2 \%)$ & $26(78.8 \%)$ & \\
\hline Intermediate & $170(42.7 \%)$ & $35(20.6 \%)$ & $135(79.4 \%)$ & \\
\hline Central & $190(47.7 \%)$ & $34(17.9 \%)$ & $156(82.1 \%)$ & \\
\hline Immigration & & & & 0.8 \\
\hline New Immigrant> 89 & $28(7.0 \%)$ & $5(17.9 \%)$ & $23(82.1 \%)$ & \\
\hline Native-born and established immigrants & $370(93.0 \%)$ & $73(19.7 \%)$ & $297(80.3 \%)$ & \\
\hline Number of children & & & & 0.638 \\
\hline No children & $97(24.4 \%)$ & 19 (19.6\%) & $78(80.4 \%)$ & \\
\hline 1-2 children & $152(38.2 \%)$ & $33(21.7 \%)$ & $119(78.3 \%)$ & \\
\hline 3 children & $112(28.1 \%)$ & $18(16.1 \%)$ & $94(83.9 \%)$ & \\
\hline $4+$ children & $36(9.0 \%)$ & $8(22.2 \%)$ & $28(77.8 \%)$ & \\
\hline Medical staff & & & & 0.5 \\
\hline yes & $44(11.1 \%)$ & $7(15.9 \%)$ & $37(84.1 \%)$ & \\
\hline no & $354(88.9 \%)$ & $71(20.1 \%)$ & $283(79.9 \%)$ & \\
\hline \multicolumn{5}{|l|}{ Health related characteristics } \\
\hline Chronic Disease & & & & $0.023^{*}$ \\
\hline No chronic disease & $332(83.4 \%)$ & $70(21.1 \%)$ & $262(78.9 \%)$ & \\
\hline Chronic disease & $66(16.6 \%)$ & $8(12.1 \%)$ & $58(87.9 \%)$ & \\
\hline
\end{tabular}


Table 2 Characteristics of respondents by intention to get vaccinated against COVID-19 $(n=398)$ (Continued)

\begin{tabular}{|c|c|c|c|c|}
\hline & $\begin{array}{l}\text { All subjects } \\
(n=398)\end{array}$ & $\begin{array}{l}\text { DO not intend to get vaccinated } \\
\text { against COVID-19 } \\
N=78(20 \%)\end{array}$ & $\begin{array}{l}\text { Intend to get vaccinated } \\
\text { against COVID-19 } \\
N=320(80 \%)\end{array}$ & $p$-value \\
\hline & N (\%) & $\mathrm{N}(\%)$ & N (\%) & \\
\hline Smoking & & & & 0.078 \\
\hline Yes & $44(11.1 \%)$ & $13(29.5 \%)$ & $31(70.5 \%)$ & \\
\hline No/quitted & $349(87.7 \%)$ & $64(18.3 \%)$ & $285(81.7 \%)$ & \\
\hline Over weight & & & & $<0.001^{*}$ \\
\hline Yes & $128(32.2 \%)$ & $14(10.9 \%)$ & $114(89.1 \%)$ & \\
\hline No & $247(62.1 \%)$ & $62(25.1 \%)$ & $185(74.9 \%)$ & \\
\hline COVID-19 past disease & & & & 0.693 \\
\hline Yes & $8(2.0 \%)$ & $2(25.0 \%)$ & $6(75.0 \%)$ & \\
\hline No & $371(93.2 \%)$ & $72(19.4 \%)$ & $299(80.6 \%)$ & \\
\hline Influenza last year & & & & 0.295 \\
\hline yes & $43(10.8 \%)$ & $11(25.6 \%)$ & $32(74.4 \%)$ & \\
\hline no & 355 (89.2\%) & $67(18.9 \%)$ & $288(81.1 \%)$ & \\
\hline Influenza vaccine last year & & & & $<0.001^{*}$ \\
\hline No & 205 (51.5\%) & 69 (33.7\%) & $136(66.3 \%)$ & \\
\hline yes & $193(48.5 \%)$ & $9(4.7 \%)$ & $184(95.3 \%)$ & \\
\hline Perceived health status & & & & 0.079 \\
\hline Very good & $295(74.1 \%)$ & $64(21.7 \%)$ & $231(78.3 \%)$ & \\
\hline Good & $89(22.4 \%)$ & $14(15.7 \%)$ & $75(84.3 \%)$ & \\
\hline Not so good & $14(3.5 \%)$ & $0(0.0 \%)$ & 14 (100.0\%) & \\
\hline
\end{tabular}

Note: Percentages of "DO not Intend to get vaccinated against COVID-19" and "Intend to get vaccinated against COVID-19" are calculated as valid \% per each row (i.e., each row sums up to $100 \%$, without missing values) ${ }^{*} p<0.05$

Table 3 Univariate analyses between HBM and TPB variables and the intention to get vaccinated against COVID-19

\begin{tabular}{|c|c|c|c|c|c|}
\hline & $\begin{array}{l}\text { DO not intend to get vaccinated } \\
(n=78)\end{array}$ & $\begin{array}{l}\text { Intend to get vaccinated } \\
(n=320)\end{array}$ & t-test & $P$ value (two-tail) & Effect size \\
\hline HBM covariates & Mean (SD) & Mean (SD) & & & Cohen's d \\
\hline Perceived Susceptibility & $2.89(1.54)$ & $4.94(1.12)$ & -11.09 & 0.00 & 1.52 \\
\hline Perceived Severity & $2.48(1.24)$ & $3.36(1.33)$ & -5.28 & 0.00 & 0.68 \\
\hline Perceived Benefits & $3.10(1.44)$ & $5.37(0.79)$ & -13.41 & 0.00 & 1.95 \\
\hline Perceived Barriers & $2.55(1.59)$ & $2.42(1.51)$ & 0.70 & 0.48 & 0.08 \\
\hline Cues to action & $2.51(1.33)$ & $4.16(1.26)$ & -10.25 & 0.00 & 1.27 \\
\hline Health motivation & $4.03(1.51)$ & $4.08(1.36)$ & -0.32 & 0.75 & 0.03 \\
\hline \multicolumn{6}{|l|}{ TPB covariates } \\
\hline Attitude & $2.55(1.59)$ & $2.42(1.52)$ & 0.70 & 0.48 & 0.08 \\
\hline Subjective norms & $3.49(1.36)$ & $5.16(0.85)$ & -10.42 & 0.00 & 1.47 \\
\hline PBC & $4.91(1.51)$ & $5.08(1.24)$ & -0.95 & 0.35 & 0.12 \\
\hline Self-efficacy & $3.53(1.44)$ & $5.20(1.06)$ & -9.67 & 0.00 & 1.32 \\
\hline
\end{tabular}

COVID-19 vaccination intention measured by the item: "I want to get vaccinated against the COVID-19 virus soon in case there is a vaccine available", on a 1-6 agreement scale 
Table 4 Hierarchical logistic regression analysis - predictors of intention to get vaccinated against COVID-19 $(n=398)$

\begin{tabular}{|c|c|c|c|c|c|c|c|c|c|}
\hline \multirow[t]{2}{*}{ Predictor variables } & \multicolumn{3}{|c|}{$\begin{array}{l}\text { Model 1: sociodemographic, } \\
\text { health-related, and HBM variables }\end{array}$} & \multicolumn{3}{|c|}{$\begin{array}{l}\text { Model 2: sociodemographic, } \\
\text { health-related, and TPB variables }\end{array}$} & \multicolumn{3}{|c|}{$\begin{array}{l}\text { Model 3: sociodemographic, } \\
\text { health-related, HBM and TPB } \\
\text { variables }\end{array}$} \\
\hline & $\overline{R^{2}}$ & OR $(95 \% \mathrm{Cl})$ & $p$ Value & $\overline{R^{2}}$ & OR $(95 \% \mathrm{Cl})$ & $p$ Value & $\overline{R^{2}}$ & OR $(95 \% \mathrm{Cl})$ & $p$ Value \\
\hline Block 1: Sociodemographic & 0.12 & & & 0.12 & & & 0.12 & & \\
\hline \multicolumn{10}{|l|}{ Gender } \\
\hline Female & & Reference & & & Reference & & & Reference & \\
\hline Male & & $4.35(1.58-11.93)$ & 0.00 & & $1.94(0.85-4.45)$ & 0.12 & & $3.23(1.05-9.97)$ & 0.04 \\
\hline \multicolumn{10}{|l|}{ Education } \\
\hline Non-academic & & Reference & & & Reference & & & Reference & \\
\hline Academic & & $3.54(1.44-8.67)$ & 0.01 & & $3.35(1.56-7.21)$ & 0.00 & & $3.67(1.38-9.78)$ & 0.01 \\
\hline Block 2: health-related & 0.29 & & & 0.29 & & & 0.29 & & \\
\hline \multicolumn{10}{|l|}{ Influenza vaccination last year } \\
\hline Not-vaccinated for flu last year & & Reference & & & Reference & & & Reference & \\
\hline Vaccinated for flu last year & & $3.69(1.35-10.08)$ & 0.01 & & $8.21(3.15-21.43)$ & 0.00 & & $3.90(1.26-12.07)$ & 0.02 \\
\hline Block 3 model 1: HBM & 0.74 & & & & & & 0.74 & & \\
\hline Cues to action & & $1.99(1.38-2.87)$ & 0.00 & & & & & $1.97(1.35-2.86)$ & 0.00 \\
\hline Benefits & & $4.49(2.79-7.22)$ & 0.00 & & & & & $3.68(2.21-6.13)$ & 0.00 \\
\hline Perceived Severity & & $2.36(1.58-3.51)$ & 0.00 & & & & & $2.44(1.61-3.72)$ & 0.00 \\
\hline Block 3 model 2: TPB & & & & 0.64 & & & & & \\
\hline Self-efficacy & & & & & $2.05(1.54-2.72)$ & 0.00 & & $1.82(1.22-2.70)$ & 0.00 \\
\hline Subjective Norms & & & & & $3.04(2.15-4.30)$ & 0.00 & & $1.75(1.06-2.87)$ & 0.03 \\
\hline Block 4 model 3: HBM \&TPB & & & & & & & 0.78 & & \\
\hline
\end{tabular}

Model 1: R2 = 0.464 (Cox and Snell); 0.738 (Nagelkerke). Model 2: R2 = 0.4 (Cox and Snell); 0.637 (Nagelkerke), Model 3: R2 = 0.49 (Cox and Snell); 0.781 (Nagelkerke)

regression were the HBM dimensions, which added $45 \%$ to the explained variance, on top of the $29 \%$ explained by the demographic and health-related characteristics. According to this model, two demographic variables, gender and education, were associated with intention to get vaccinated against COVID-19. Men intended to receive COVID-19 vaccine more than woman $(\mathrm{OR}=4.35$, 95\% CI 1.58-11.93) and educated respondents intended to receive COVID-19 vaccine more than non-educated respondents ( $\mathrm{OR}=3.54,95 \% \mathrm{CI} 1.44-8.67)$. Only one health-related variable, i.e., having received influenza vaccine last year, was a significant predictor. Respondents who had received the seasonal influenza vaccine in the previous year were 3.3-fold significantly more likely to intend to get vaccinated against COVID-19, as compared with those who had not received the seasonal influenza vaccine in the previous year $(\mathrm{OR}=3.31,95 \% \mathrm{CI}$ 1.22-9.00).

From the HBM, perceived benefits, cues to action, and perceived severity were significant predictors of intention to get vaccinated against COVID-19. Two perceived benefits, namely, "COVID-19 vaccine will have high efficacy in preventing significant suffering and complications of the disease" and "I believe that if I get vaccinated against COVID-19, the risk of getting infected with the disease or infecting others will decrease", were significant predictors of intention to receive COVID-19 vaccine (OR $=4.49$, 95\% CI 2.79 7.22); Two perceived severity statements, namely, "Even if I will get infected with COVID-19, I do not think it will cause me significant suffering or complications" and "Even if I get infected with COVID-19, the likelihood of recovering from the disease is very high" were also significant predictors of intention to get vaccinated against COVID-19 (OR $=2.36,95 \% \mathrm{CI}$ 1.58-3.51). Finally, five cues to action: "The chances of me getting vaccinated against COVID-19 will increase if opinion leaders on social media, friends and family advise so, official guidelines from the Ministry of Health are published and if a GP recommends vaccination", were also found as significant predictors of the intention to receive COVID-19 vaccine (OR = 1.99, 95\% CI 1.38-2.87). Susceptibility perceptions (i.e., beliefs concerning the likelihood of someone getting sick from COVID-19 if not getting vaccinated), perceived barriers (time/money) and health motivation (exercise and healthy diet) were not associated with intention to get receive COVID-19 vaccine. 
The second model considered in this study, which included TPB variables as well as demographic and healthrelated factors (Table 4; model 2), explained $64 \%$ of the variance in intention to receive COVID-19 vaccine (adjusted $\mathrm{R}$ squared $=0.64$ ). The TPB model added $35 \%$ to the explained variance on top of the $29 \%$ explained by the demographic and health characteristics (Table 4; model 2). According to the TPB model, subjective norms and self-efficacy were significant predictors of intention to get vaccinated against COVID-19. Two subjective norms, namely, "Most of my friends will support the COVID-19 vaccine" and "If I tell my friends and relatives that I intend to get vaccinated against COVID-19 when a vaccine is available, they will respond positively" were significant predictors of intention to receive COVID-19 vaccine $(\mathrm{OR}=3.04,95 \% \mathrm{CI} 2.15-4.30)$. Self-efficacy was also a significant predictor of intention to receive COVID-19 vaccine $(\mathrm{OR}=2.05,95 \%$ CI $1.54-2.72)$. PBC and attitude were not significant predictors of intention to receive COVID-19 vaccine.

When key variables from both the HBM and TPB models were entered into a hierarchical regression model (Table 4; model 3), all of the existing relationships remained significant. The combination of HBM and TPB predictor variables, together with demographic and health-related factors, explained $78 \%$ of the variance in intention to get vaccinated against COVID-19 (adjusted $\mathrm{R}$ squared $=0.78$ ). Stated differently, adding the TPB predictor variables, on top of the predictor variables, considered in the first model, added $4 \%$ to the overall explained variance.

\section{Discussion}

The present study examined the intentions of the general public to receive a future COVID-19 vaccine, and investigated various sociodemographic, health-related and behavioral predictors for these intentions based on the combined use of the HBM and TPB models. In examining these predictors, some were found to be consistent with the results of previous efforts (e.g., age, gender and educational level). At the same time, I have identified other predictors that have not been previously reported in the context of COVID-19 (e.g., chronic diseases, over-weight, vaccination against influenza in the previous season, self-efficacy, and subjective norms).

The overall intention to receive a COVID-19 vaccine found in the present study was very high $(80 \%)$. This result is consistent with the findings of Dror et al., who showed a vaccine acceptance rate of $75 \%$ in the entire Israeli population [9], and are also similar to those of Reiter et al. [8], who found that $69 \%$ of participants in the United States were willing to receive a COVID-19 vaccine, and to those of Wong et al. [26] showing that $48 \%$ of participants definitely intend to receive the vaccine, in addition to the $30 \%$ who probably intend to receive the vaccine.

Higher rates of vaccination intention were reported among participants aged 65 years and above (93\%), similar to earlier work reporting an acceptance rate of $91.3 \%$ among Chinese adults [31]. It is reasonable to find higher intention of vaccination among respondents in this age group, as they are also included in the high-risk group for COVID-19. In contrast, lower intention was found for participants aged below 65 as well as in other sociodemographic groups, including females and nonacademics, similar to what was seen in Fisher et al. and Neumann-Böhme et al. [6, 32].

I also examined several predictors that may predict an intention to receive a COVID-19 vaccine, which had apparently not been previously reported in the literature in the context of COVID-19 vaccine acceptance. With regard to sociodemographic and health-related predictors, the present study found that respondents with chronic conditions at higher risk of COVID-19 or those overweighted, as well as those who reported having been vaccinated against influenza in the previous season were more likely to accept a COVID-19 vaccine. While several other sociodemographic and health-related predictors were considered, none were found to be significant in terms of the intention to receive a COVID-19 vaccine. These included demographic considerations, such as personal status, socio-economic level, residence in the periphery, being an immigrant, number of children and health-related contrasts, such as perceived health status, or having been infected with COVID-19 or influenza in the previous year.

Regarding the use of theoretical behavior models, this is apparently the first study to use the TPB model to predict intention to receive a COVID-19 vaccine. The theoretical framework at the heart of the present study included demographic variables, health-related factors and the combined use of the HBM and TPB models. This unified model was able to explain $78 \%$ of the variance in the intention to receive a COVID-19 vaccine, which was considerably higher compared to using each of the two behavior models separately. According to HBM, perceived benefits, cues to action, and perceived severity were the most significant predictors of the intention to receive a COVID-19 vaccine. The findings regarding disease severity indicate that those who intend to get vaccinated view themselves as being at high risk of significant suffering or experiencing complications should they be infected with COVID-19, as compared to those who do not intend to get vaccinated. This indicates the need to increase risk perception and severity among the public, especially among those who perceive the disease as being non-dangerous. Regarding cues to action, significant predictors which increased the 
intention to COVID-19 vaccine were recommendations from the Ministry of Health and GP or carrying out the vaccination at the place of work. These observations are similar to findings reported by Reiter et al., who suggested provider recommendation as being a key determinant of vaccination behavior in terms of promoting the vaccine [8]. Regarding the benefits, those who intend to receive the vaccine see high perceived benefits in obtaining the COVID-19 vaccine for protecting themselves and others, similar to what Dror et al. reported, implying that vaccination compliance relies on a personal risk-benefit perception [9]. Finally, according to the TPB model, subjective norms and self-efficacy were found to be significant predictors of the intention to get vaccinated against COVID-19. Subjective norms that especially drove respondents were when friends and relatives positively responded to the vaccination.

Our findings underscore the importance of setting up intervention plans to deal with respondents with low intentions of receiving the vaccine so as to ensure high actual vaccination uptake, especially among high-risk groups. Specifically, in future vaccine programs, efforts should be made to target females, non-academics, and those who did not vaccinate against influenza in the previous season. Moreover, public health intervention programs should put more focus on increasing the perception of vaccination benefits and the perceived severity of the disease. Several cues to actions should also be considered, such as investing more resources in information campaigns by the Ministry of Health and in making vaccination available at the workplace. In terms of subjective norms, efforts should be made to encourage individuals to share their positive thoughts and experience with regard to COVID-19 vaccination with their friends and relatives, for example by providing them an easy platform to share the time and location of their vaccination in social media.

Although this study was conducted in Israel, I believe that most of our findings can be generalized to other countries as well. Nevertheless, with regard to the risk perception predictors, it is important to note that the Israeli government has invested many efforts in conveying the risk of being infected with COVID-19 and of its potential complications to the public. Moreover, this study was conducted after the first lockdown in Israel, what further emphasizes the potential consequences of the disease.

The COVID-19 epidemic has had an effect not only on vaccination against this disease but also on readiness to receive other vaccines, such as that against influenza. Indeed, a major concern for the coming winter is the combination of COVID-19 and influenza. Previous studies have demonstrated how an influenza pandemic can increase seasonal influenza vaccination acceptance [15], however, it is not clear whether the COVID-19 pandemic has affected influenza vaccine acceptance among the general public. Only few recent studies showed a change in terms of intention to accept seasonal influenza vaccination during the 2019 coronavirus disease pandemic among nurses in Hong Kong, China [31]. Moreover, a study conducted in 17 pediatric emergency departments in 6 countries demonstrated an increase of $15.8 \%$ in the number of caregivers who stated they plan to vaccinate their children against influenza, relative to the previous year [33]. The findings of the present study show that the COVID-19 pandemic may have influenced intentions to receive the seasonal influenza vaccine in the general public. Half of the respondents reported that they had decided not to receive influenza vaccine in the previous season, yet only $40 \%$ of the respondents indicated that they would be willing to receive an influenza vaccine in the coming winter and $66 \%$ reported they intend to receive a COVID-19 vaccine.

\section{Limitations}

It is important to recognize study limitations when interpreting the results reported here. One limitation of this study is that a convenience sample of participants was recruited via an online survey. Although the demographic characteristics of study participants were similar to those of the general Israeli population, this limitation should be considered in interpreting the results of the study, as our sample population does not include those minorities who do not have high access to online surveys, such as the ultra-Orthodox and Arabs. Additional limitations come from the fact that in the survey used here, vaccination intention was assessed under the assumption that COVID-19 vaccine will be free or covered by basic health insurance. According to Israeli health policy, influenza vaccine is covered by the basic basket of services. Hence, it is reasonable to assume that the COVID-19 vaccine will be similarly covered as part of a budget for preventive services in public health. Moreover, the study used self-report of influenza vaccine acceptance in the previous season and intention to influenza vaccine in the coming winter and COVID-19 vaccine once available. Self-report of actual behavior may be biased, unlike monitoring actual vaccination. Finally, the study used a cross-sectional observational design that does not allow to derive any causal conclusions. Therefore, it cannot be ruled out that other variables created pseudo-correlations.

\section{Conclusions}

This study provides up-to-date survey data on the intention of the general public to vaccinate against COVID-19, and on the sociodemographic, health-related and behavioral predictors for these intentions, based on 
the combined use of the HBM and TPB models. Our results highlight that while many adults are willing to receive a COVID-19 vaccine, vaccination intentions differ according to a number of sociodemographic, healthrelated and behavioral characteristics including: gender, educational level, vaccination against influenza in the previous season, high perceived benefits, high perceived severity, cues to action, subjective norms and selfefficacy.

These findings are important for health policy makers and healthcare providers and can help better guide COVID-19 vaccine compliance. Specifically, efforts should be made to target females, non-academics, and those who did not vaccinate against influenza in the previous season. Moreover, public health intervention programs should put more focus on increasing the perception of vaccination benefits and the perceived severity of the disease. Finally, more resources should be invested in information campaigns by the Ministry of Health, in making vaccination available at the workplace, and in encouraging individuals to share their positive thoughts and experience with regard to COVID-19 vaccination.

As a final note, the current study examined whether people will accept a future COVID-19 vaccine when such becomes available. Further research should examine the lag of time of acceptance now that such a vaccine is available.

\section{Abbreviations}

HBM: Health Belief Model; TPB: Theory of Planned Behavior

\section{Acknowledgements}

Not applicable.

\section{Author's contributions}

LS was responsible for study conception and design, data collection and analysis, and wrote the manuscript. The author(s) read and approved the final manuscript.

\section{Author's information}

Liora Shmueli is a lecturer in the Department of Management, Bar-Ilan University.

\section{Funding}

Not applicable.

\section{Availability of data and materials}

The datasets generated during the current study are not publicly available but are available from the corresponding author on reasonable request.

\section{Declarations}

\section{Ethics approval and consent to participate}

The study was approved by the Ethics Committee for Non-clinical Studies at Bar Ilan-University in Israel. The ethics form was signed by the committee head on May 11, 2020.

Informed consent for participating in the study was obtained digitally through Google Forms from all subjects, and all methods were carried out in accordance with the relevant guidelines and regulations of the Ethics Committee for Non-clinical Studies at Bar llan-University in Israel. Specifically, at the beginning of the questionnaire, participants were asked whether they agree to participate in the research and whether they were 18 years old or older to be included in the study. Only participants which answered these two questions positively were able to continue with the questionnaire. Participants were also informed that their participation was voluntary and that they had the right to leave at any time without providing any explanation. No incentives were provided to the study participants.

\section{Consent for publication}

Not applicable.

\section{Competing interests}

The author declares that she has no competing interests.

Received: 20 December 2020 Accepted: 1 April 2021

Published online: 26 April 2021

\section{References}

1. Cucinotta D, Vanelli M. WHO Declares COVID-19 a Pandemic. Acta Bio Medica Atenei Parm. 2020;91:157-60. https://doi.org/10.23750/abm.v91 i1.9397.

2. WHO. More than 150 countries engaged in COVID-19 vaccine global access facility. 2020. https://www.who.int/news/item/15-07-2020-more-than-150countries-engaged-in-covid-19-vaccine-global-access-facility. Accessed 13 Oct 2020.

3. The U.S. Food and Drug Administration. COVID-19 Vaccines: FDA; 2021 https://www.fda.gov/emergency-preparedness-and-response/coronavirusdisease-2019-covid-19/covid-19-vaccines\#eua-vaccines.

4. Israel eases restrictions following vaccine success. BBC News. 2021 https://www.bbc.com/news/world-middle-east-56143126. Accessed 11 Mar 2021.

5. MacDonald NE. Vaccine hesitancy: definition, scope and determinants. Vaccine. 2015;33(34):4161-4. https://doi.org/10.1016/j.vaccine.2015.04.036.

6. Neumann-Böhme S, Varghese NE, Sabat I, Barros PP, Brouwer W, van Exel J, et al. Once we have it, will we use it? A European survey on willingness to be vaccinated against COVID-19. Eur J Health Econ. 2020;21(7):977-82. https://doi.org/10.1007/s10198-020-01208-6.

7. Dodd RH, Cvejic E, Bonner C, Pickles K, McCaffery KJ; Sydney Health Literacy Lab COVID-19 group. Willingness to vaccinate against COVID-19 in Australia. Lancet Infect Dis. 2020. https://doi.org/10.1016/s1473-3099(20)30559-4.

8. Reiter PL, Pennell ML, Katz ML. Acceptability of a COVID-19 vaccine among adults in the United States: how many people would get vaccinated? Vaccine. 2020;38(42):6500-7. https://doi.org/10.1016/j.vaccine.2020.08.043.

9. Dror AA, Eisenbach N, Taiber S, Morozov NG, Mizrachi M, Zigron A, et al. Vaccine hesitancy: the next challenge in the fight against COVID19. Eur J Epidemiol. 2020;35(8):775-9. https://doi.org/10.1007/s10654-02 0-00671-y.

10. Bish A, Yardley L, Nicoll A, Michie S. Factors associated with uptake of vaccination against pandemic influenza: a systematic review. Vaccine. 2011; 29(38):6472-84. https://doi.org/10.1016/j.vaccine.2011.06.107.

11. Schmid P, Rauber D, Betsch C, Lidolt G, Denker M-L. Barriers of Influenza Vaccination Intention and Behavior - A Systematic Review of Influenza Vaccine Hesitancy, 2005-2016. PLoS One. 2017;12(1):e0170550. https://doi. org/10.1371/journal.pone.0170550.

12. Velan B, Kaplan G, Ziv A, Boyko V, Lerner-Geva L. Major motives in nonacceptance of a/H1N1 flu vaccination: The weight of rational assessment. Vaccine. 2011;29(6):1173-9. https://doi.org/10.1016/j.vaccine.2010.12.006.

13. Fabry P, Gagneur A, Pasquier J-C. Determinants of a (H1N1) vaccination: cross-sectional study in a population of pregnant women in Quebec. Vaccine. 2011;29(9):1824-9. https://doi.org/10.1016/j.vaccine.2010.12.109.

14. Schwarzinger M, Flicoteaux R, Cortarenoda S, Obadia Y, Moatti J-P. Low acceptability of a/H1N1 pandemic vaccination in French adult population: did public health policy fuel public dissonance? PLoS One. 2010;5(4):e10199. https://doi.org/10.1371/journal.pone.0010199.

15. Rubin G, Potts $H$, Michie $S$. The impact of communications about swine flu (influenza a H1N1v) on public responses to the outbreak: results from 36 national telephone surveys in the UK. Health Technol Assess. 2010;14(34): 183-266. https://doi.org/10.3310/hta14340-03.

16. Rosenstock IM. Why people use health services. Milbank Mem Fund Q 1966; 44:Suppl:94-127. http://www.ncbi.nlm.nih.gov/pubmed/5967464. Accessed 4 Sep 2011, DOI: https://doi.org/10.2307/3348967. 
17. Kan T, Zhang J. Factors influencing seasonal influenza vaccination behaviour among elderly people: a systematic review. Public Health. 2018;156:67-78. https://doi.org/10.1016/j.puhe.2017.12.007.

18. Rosenstock. Social Learning Theory and the Health Belief Model. 1988. https://journals.sagepub.com/doi/abs/10.1177/109019818801500203?casa_ token=8sh1gfDhinIAAAAA:OLFrlO2JbhMy961na4

XkKffFCWpFwHuZKJCwpjviTU1uNYjzxXrQ_ak9r7oNIBEjODPmXrrTXdA4. Accessed 15 Oct 2020.

19. Yang ZJ. Predicting young adults' intentions to get the H1N1 vaccine: an integrated model. J Health Commun. 2015;20(1):69-79. https://doi.org/10.1 080/10810730.2014.904023

20. Shahrabani S, Benzion U, Din GY. Factors affecting nurses' decision to get the flu vaccine. Eur J Health Econ. 2009;10(2):227-31. https://doi.org/10.1 007/s10198-008-0124-3.

21. Aizen I, Fishbein M. Attitude-behavior relations: A theoretical analysis and review of empirical research. Psychol Bull. 1977;84(5):888-918. https://doi. org/10.1037/0033-2909.84.5.888.

22. Liao Q, Cowling BJ, Lam WWT, Fielding R. Factors affecting intention to receive and self-reported receipt of 2009 pandemic (H1N1) vaccine in Hong Kong: a longitudinal study. PLoS One. 2011;6(3):e17713. https://doi.org/10.13 71/journal.pone.0017713.

23. McClenahan C, Shevlin M, Adamson G, Bennett C, O'Neill B. Testicular self-examination: a test of the health belief model and the theory of planned behaviour. Health Educ Res. 2007;22(2):272-84. https://doi.org/1 0.1093/her/cyl076

24. Lau JTF, Yeung NCY, Choi KC, Cheng MYM, Tsui HY, Griffiths S. Factors in association with acceptability of a/H1N1 vaccination during the influenza a/ H1N1 pandemic phase in the Hong Kong general population. Vaccine. 2010;28(29):4632-7. https://doi.org/10.1016/j.vaccine.2010.04.076.

25. Myers $L B$, Goodwin R. Using a theoretical framework to determine adults' intention to vaccinate against pandemic swine flu in priority groups in the UK. Public Health. 2012;126:S53-6. https://doi.org/10.1016/j.puhe.2012.05.024

26. Wong et al. Full article: The use of the health belief model to assess predictors of intent to receive the COVID-19 vaccine and willingness to pay. 2020. https://www.tandfonline.com/doi/full/10.1080/21645515.2020.1790279. Accessed 26 Oct 2020.

27. Lin C-Y, Imani V, Majd NR, Ghasemi Z, Griffiths MD, Hamilton K, et al. Using an integrated social cognition model to predict COVID-19 preventive behaviours. Br J Health Psychol. 2020;25(4):981-1005. https://doi.org/1 $0.1111 /$ bjhp. 12465

28. Thu TPB, Ngoc PNH, Hai NM, Tuan LA. Effect of the social distancing measures on the spread of COVID-19 in 10 highly infected countries. Sci Total Environ. 2020;742:140430. https://doi.org/10.1016/j.scitotenv.2020.140430.

29. CDCx. COVID-19 Guidance for Older Adults. 2021. https://www.cdc.gov/a ging/covid19-guidance.html. Accessed 13 Mar 2021.

30. Taherdoost $\mathrm{H}$. What is the best response scale for survey and questionnaire design; review of different lengths of rating scale / attitude scale / Likert scale. SSRN scholarly paper. Rochester;: Social Science Research Network; 2019. https://papers.ssrn.com/abstract=3588604. Accessed 11 Mar 2021.

31. Wang K, Wong ELY, Ho KF, Cheung AWL, Chan EYY, Yeoh EK, et al. Intention of nurses to accept coronavirus disease 2019 vaccination and change of intention to accept seasonal influenza vaccination during the coronavirus disease 2019 pandemic: a cross-sectional survey. Vaccine. 2020;38(45):704956. https://doi.org/10.1016/j.vaccine.2020.09.021.

32. Fisher KA, Bloomstone SJ, Walder J, Crawford S, Fouayzi H, Mazor KM. Attitudes Toward a Potential SARS-CoV-2 Vaccine: A Survey of U.S. Adults. Ann Intern Med. 2020. https://doi.org/10.7326/M20-3569.

33. Goldman RD, McGregor S, Marneni SR, Katsuta T, Griffiths MA, Hall JE, et al. Willingness to vaccinate children against influenza after the coronavirus disease 2019 pandemic. J Pediatr. 2020;228:87-93.e2. https://doi.org/10.10 6/j.jpeds.2020.08.005

\section{Publisher's Note}

Springer Nature remains neutral with regard to jurisdictional claims in published maps and institutional affiliations.

\section{Ready to submit your research? Choose BMC and benefit from:}

- fast, convenient online submission

- thorough peer review by experienced researchers in your field

- rapid publication on acceptance

- support for research data, including large and complex data types

- gold Open Access which fosters wider collaboration and increased citations

- maximum visibility for your research: over $100 \mathrm{M}$ website views per year

At BMC, research is always in progress.

Learn more biomedcentral.com/submissions 